\title{
Lehen mailako arretaren eta hematologiako kontsultaren arteko deribazio- eta kudeaketa-irizpideak
}

\section{Primary Care and the Haematology Department: Referral and management criteria}

Izaskun Ceberio $^{1,2}$, Jose Ramon Furundarena ${ }^{1,2}$, Nerea Uresandi ${ }^{1,2}$, Larraitz Arrue ${ }^{3}$, Hodei Arrizabalaga ${ }^{4}$, Ana Jesus Gonzalez ${ }^{5}$, Enrique Contreras ${ }^{2}$, Ana Isabel Diez ${ }^{2}$, Elena Suquia ${ }^{5,2}$, Andoni Orube 2 , Maria Araiz ${ }^{1,2}$

${ }^{1}$ Hematologia Zerbitzua. Donostia Unibertsitate Ospitalea

${ }^{2}$ Donostia Onkologia eta Hematologia Institutua-DOHI

${ }^{3}$ Donostialdea ESIko familia-medikua

${ }^{4}$ Hematologia Zerbitzua. Mendaro Ospitalea

${ }^{4}$ Tolosaldea ESIko familia-medikua

${ }^{5}$ Kalitate Zerbitzua. Donostia Unibertsitate Ospitalea

izaskun.ceberioechechipia@osakidetza.eus

\section{Laburpena}

Donostia Unibertsitate Ospitaleko hematologiako kontsultetan 2015. urtean hobekuntza-planaren diseinuan lanean hasi ginen. Konturatu ginen bertan artatzen ziren kasu askok ez ziotela baliorik eransten, ez baitzuten patologia hematologikorik.

Hematologiako kontsultetara bereziki lehen arretatik iristen ziren pazienteak. Kontsultaren arrazoi usuena alterazio analitiko bat agertzea zen, hain zuzen kasuen $\% 60 \mathrm{k}$ analitikan sei alterazio hauetako bat zuen: gammapatia monoklonala, leukozitosia, linfozitosia, neutropenia, monozitosia edo/eta tronbozitosia.

Hematologiako eta lehen arretako medikuz eta erizainez osatutako lantalde bat sortu genuen. Sei alterazio analitiko horiek oinarri hartuta, dokumentu bat adostu zen. Dokumentu horretan idatzi ziren alterazio hematologiko horietako bat edo gehiago agertzen zuten pertsonei zer azterketa egin behar zitzaien eta lehen mailako osasun-zentroan ala hematologiako kontsultetan egin behar zitzaien jarraipena.

Ondoren, Donostialdea ESIko zenbait zentrotan aurkezpen-bilerak egin ziren eta bertan jasotako iritziekin behin betiko dokumentua adostu zen. Artikulu honetan bildu ditugu dokumentu horretan jasotako irizpideak. Dokumentua dinamikoa izatea nahi genuke eta erabilerarekin sortuko diren galderekin edo moldatu beharreko puntuekin dokumentua berritu eta eguneratuko dugu.

Hitz gakoak: gammapatia monoklonala, leukozitosia, linfozitosia, neutropenia, monozitosia, tronbozitosia.

\section{Abstract}

In 2015, we started working on the Improvement Plan of the Outpatient Clinic of the Hematology Department of the Donostia University Hospital. We noticed that many of the cases referred from primary care to the Hematology Department were inappropriate referrals as they had no hematological pathology. An analytical alteration was the main reason for referring patients from primary care. $60 \%$ of referred patients presented with one or more of the following 6 alterations according to their blood test: monoclonal gammopathy, leukocytosis, lymphocytosis, neutropenia, monocytosis and/or thrombocytosis. We set up a working group composed of primary care and 
Jat. art. Ceberio, Furundarena, Uresandi, Arrue, Arrizabalaga, Glez, Contreras,Diez, Sukia, Orube, Araiz

hematological physicians and nurses. Together, we elaborated guidelines for the referral of patients presenting with any of these 6 analytical alterations. In this document, we suggested a series of studies to be carried out in Primary Care prior to referral, and indicate if follow-up should be carried out in a Primary Care center or in the Hematology Department. We presented this initial document in the Primary Care centers of Donostia and incorporated feedback into a final document. We would like this document to be dynamic and we will modify and update it with suggestions that emerge in response to its use.

Key words: monoclonal gammopathy, leukocytosis, lymphocytosis, neutropenia, monocytosis and thrombocytosis

Bidalia: 2017ko urriaren 24an.

http://doi.org/10.26876/osagaiz.2.2017.107

Onartua: 2017ko azaroaren 14an.

\section{Sarrera}

Pazienteak artatzeko lehen lerroa lehen mailako osasun-zentroetan dago eta beharrezkoa denean kontsulta espezializatuetara edo/eta batzuetan ospitalizazioa bideratzea beharrezkoa izango da. Oso garrantzitsua da gaixoak patologiaren arabera ondo banatzea lehen mailan edo kontsulta espezializatuetan artatuak izan daitezen.

Donostia Unibertsitate Ospitaleko hematologiako kontsultetan 2015. urtean hobekuntza-planaren diseinuan lanean hasi ginenean konturatu ginen bertan artatzen ziren kasu askok analisietan ohiko parametroetatik kanpo zegoen balio bat zutela eta ez benetako patologia hematologikoa. Inoiz edo probabilitate oso baxuarekin gaixotasun hematologiko bat garatuko zuen paziente multzoari gaixotasun hematologikoaren etiketa faltsua jartzeak sor zezakeen estigmak kezkaturik eta gaindiagnosia egiten ari ote ginen kezkak mugiturik, egokia iruditu zitzaigun paziente horiek lehen arretan kudeatzeko, behar izanez gero bertan jarraitzeko edota berriro hematologiako kontsultetara bideratzeko irizpideak bilduko zituen dokumentu bat idaztea.

\section{Materiala eta metodoak}

Hematologiako kontsultetara Donostia Ospitaleko beste zerbitzuetatik, Mendaroko, Bidasoako eta Zumarragako eskualdeko ospitaleetatik (horietan aldez aurretik bertako hematologoek baloratu ondoren) eta bereziki lehen arretatik iristen ziren pazienteak.

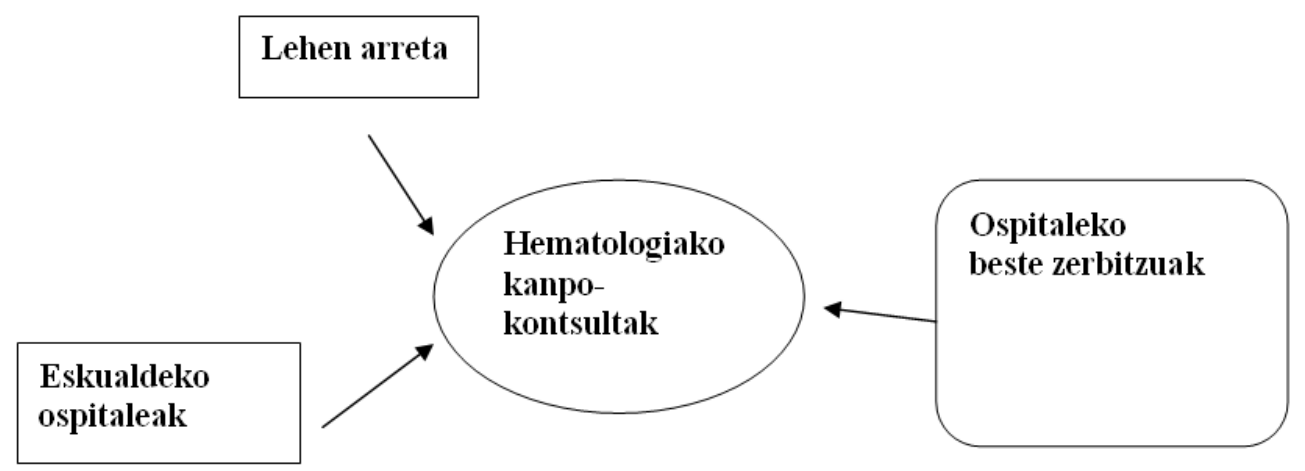

Lehen-lehenik aztertu zen zein ziren hematologiako kontsultetara bideratzen ziren pazienteen kontsultarako arrazoiak. Lehen arretatik hematologiako kanpo-kontsultetara iristen ziren paziente askoren kontsultaren arrazoia analisietan ohiko parametroetatik kanpo zegoen balio bat eta ez patologia hematologikoa zela konturatu ginen. Zehazki 1. taulan ikus daitekeen bezala, pazienteen $\% 60 \mathrm{k}$ analitikan gammapatia monoklonala, leukozitosia, linfozitosia, neutropenia, monozitosia edo/eta tronbozitosia zuen. 
Jat. art. Ceberio, Furundarena, Uresandi, Arrue, Arrizabalaga, Glez, Contreras,Diez, Sukia, Orube, Araiz

1. taula. Hematologiako kontsultetan 2015. urtean apirila eta azaroa bitartean jasotako lehen kontsulta-eskarien arrazoia.

\begin{tabular}{|l|c|}
\hline Diagnostikoa & $\mathbf{n}(\%)$ \\
\hline Proteina monoklonala & $110(\% 25)$ \\
\hline Linfozitosia & $52(\%$ 12) \\
\hline Leukozitosia & $43(\%$ 10) \\
\hline Neutropenia & $32(\% 7)$ \\
\hline Tronbozitosia & $27(\% 6)$ \\
\hline Monozitosia & $15(\% 3)$ \\
\hline Beste hemopatiak & $37(\% 8)$ \\
\hline Leuzemia linfatiko kronikoa & $25(\% 6)$ \\
\hline Ez Hodgkin linfoma & $23(\% 5)$ \\
\hline Mieloma anizkoitza & $24(\% 5)$ \\
\hline Bizitopenia pantzitopenia & $17(\% 4)$ \\
\hline Eosinofilia & $14(\% 3)$ \\
\hline Hodgkin linfoma & $10(\% 2)$ \\
\hline Esplenomegalia & $4(\% 0,9)$ \\
\hline Linfozito handi granularrak & $3(\% 0,7)$ \\
\hline Guztira & 436 \\
\hline
\end{tabular}

Hematologiako eta lehen arretako medikuz eta erizainez osatutako lantalde bat sortu genuen. Sei alterazio analitiko horiek oinarri hartu eta 2016an zehar lau bileratan lehen dokumentu bat adostu zen. Dokumentu horretan idatzi ziren alterazio hematologiko horietako bat edo gehiago agertzen zuten pertsonei zer azterketa egin behar zitzaien eta lehen mailako osasun-zentroan ala hematologiako kontsultetan egin behar zitzaien jarraipena.

Ondoren Donostialdea ESIko zenbait zentrotan hamar aurkezpen-bilera egin ziren eta bertan jasotako iritziekin behin betiko dokumentua adostu zen. Ondoren adierazten dira dokumentu horretan jasotako irizpideak.

\section{Emaitzak}

\subsection{Esanahi ezezaguneko gammapatia monoklonala (EEGM)(1-4)}

Kontuan hartu beharreko irizpide analitikoak

Honako irizpide analitiko hauek betetzen direnean:

- Proteina monoklonala serumean $<3 \mathrm{~g} / \mathrm{dL}$. 
Jat. art. Ceberio, Furundarena, Uresandi, Arrue, Arrizabalaga, Glez, Contreras,Diez, Sukia, Orube, Araiz

- Mielomak eragindako kalte organikoaren aztarnarik ez (hiperkaltzemia, giltzurrungutxiegitasuna, anemia, hezurretako lesio litikoak) eta amiloidosirik ez.

- Hezur-muineko azterketan zelula plasmatikoen kopurua < \% 10 (arrisku baxuko EEGMetan hezur-muinaren azterketa ez da beharrezkoa).

Kontuan hartu beharreko irizpide klinikoak

Paziente asintomatikoa.

Jarraipena lehen mailako osasun-zentroan egiteko irizpideak

Hasierako diagnostikoaren unean paziente guztiak hematologiako kontsultara bideratuko dira.

Hematologiako kontsultan baloratu ondoren, arrisku baxuko EEGMak osasun-zentroan kontrolatuko dira:

- Osagai monoklonala $<1,5 \mathrm{~g} / \mathrm{dL}$.

- Osagai monoklonala Glg motakoa.

- Kate arinen ratioa serumean normala $(>0,26$ edo $<1,65)$.

Ondorengo analitikak eskatuko dira 6 hilean behin osagai monoklonala 1-1,5 g/dL tartean dagoenean eta urtean behin osagai monoklonala $<1 \mathrm{~g} / \mathrm{dL}$ denean: hemograma, giltzurrun-funtzioa, kaltzioa, proteinograma eta kate arinen ratioa serumean.

Hematologiako kontsulta ez-presentziala noiz egin

Serumean edo gernuan gammapatia monoklonala diagnostikatzen zaien pazienteak hasieran hematologiako kontsultara bideratuko dira. Lehen bi kontsultak (lehenengoa eta bigarrena 3-6 hilabetera) hematologian bertan izango dira hemopatia bat dagoen ala ez jakiteko eta eboluzioa baloratzeko.

Mieloma edo arrisku altuko EEGMa diagnostikatzen bada, hurrengo kontrol guztiak hematologiako kontsultan egingo dira.

Arrisku baxuko EEGMa diagnostikatzen baldin bada, bigarren kontsultaren ondoren pazientea berriro bere osasun-zentrora bideratuko da eta bertan egingo da jarraipena. Eboluzioan ondorengo irizpideen arabera berriro hematologiako kontsultara bideratu daiteke:

- Irizpide klinikoak. Ondoren aipatzen den edozein zeinu edo sintomagatik:

- Hezurretako minak lehen aldiz agertzen direnean, lehendik zeuzkaten minak okerragotzen direnean edo lesio litikoak edo osteoporosi berria agertzen direnean beste arrazoi ezagunik gabe.

○ Plasmozitoma izan daitekeen lesio baten agerpena (parte bigunetako tumorea).

- Adenopatiak, hepatomegalia, esplenomegalia.

- B sintomak (pisu-galera, sukarra arrazoirik gabe edo izerditze nabarmena).

- Hiperbiskositatearen sintomak: buruko mina, ikusmenaren galera, tronbosia.

- Amiloidosiaren susmoa (makroglosia, sindrome nefrotikoa proteinuriarekin, kardiomiopatia murriztatzailea, proBNP-ren igoera arrazoi ezagunik gabe, beherakoa).

- Irizpide analitikoak: 
Jat. art. Ceberio, Furundarena, Uresandi, Arrue, Arrizabalaga, Glez, Contreras,Diez, Sukia, Orube, Araiz

O Osagai monoklonala $>1,5 \mathrm{~g} / \mathrm{dL}$.

- Kappa/Lambda ratioa $<0,125$ edo $>8$.

- Zitopeniak agertzen baldin badira arrazoi ezagunik gabe (anemia, tronbopenia edo leukopenia).

- Hiperkaltzemia (emaitzaren zuzenketa egin ondoren $>11,5 \mathrm{mg} / \mathrm{dL}$ edo balio normalaren goiko muga $1 \mathrm{mg} / \mathrm{dL}$ baino gehiago gainditzen denean).

- Giltzurrun-gutxiegitasun akutua: kreatinina $>2 \mathrm{mg} / \mathrm{dL}$ edo balio baxuagoa medikuaren irizpidearen arabera.

\subsection{Leukozitosia (1-2)}

\section{Kontuan hartu beharreko irizpide analitikoak}

Irizpide analitikoa: leukozitoak > 10,5 x 10\% $/$ L edo neutrofiloak > 7,5 x 10\% $/$ L.

Laborategiak odol periferikoaren morfologia egingo du kasu hauetan: leukozitoak $>30 \times 10^{9} / \mathrm{L}$ edo granulozito heldugabeak leukozitoen formulatik $>\% 5$ edo basofilia edo eosinofilia edo monozitosia edo blastoen edo linfozito anormalen alarma (morfologiaren txostenean zehaztuko da hematologiako kontsultetara deribatzea gomendatzen den ala ez).

Beste hemograma bat eta globuluen jalkiera-abiadura eskatu daitezke.

Kontuan hartu beharreko irizpide klinikoak

Kontuan hartu leukozitosi erreaktiboa sortu dezaketen arrazoiak: infekzioak, glukokortikoideak, tabakoa, gaixotasun autoimmuneak, estresa, neoplasia, haurdunaldia eta erditzea.

\section{Jarraipena lehen mailako osasun-zentroan egiteko irizpideak}

Honako kasu hauetan leukozitosiaren jarraipena osasun-zentroan bertan egingo da:

- Irizpide klinikoak: paziente asintomatikoa.

- Irizpide analitikoak: beste zitopeniarik ez dagoenean, poliglobuliarik ez, tronbozitosirik ez edo morfologian hemopatiarik atzematen ez denean.

Kasu hauetan leukozitosia moderatua baldin bada, hemograma errepikatu 4-6 astetara (kontuan hartu populazioaren \% 2,5ek leukozitoen kopurua 7,5 eta $15 \times 10^{9} / \mathrm{L}$ tartean edukitzen duela). Neutrofilia sekundarioa edo moderatua baldin bada, beste pertsonei egiten zaizkien kontrol analitiko berdinak egin.

\section{Hematologiako kontsulta ez-presentziala noiz egin}

Honako irizpide hauek baloratuko dira:

- Irizpide klinikoak. Ondoren aipatzen diren edozein zeinu edo sintomagatik: B sintomak (pisugalera, sukarra arrazoirik gabe edo izerditze nabarmena), adenopatiak, esplenomegalia edo hiperbiskositate-sintomak (buruko mina, ikusmenaren arazoak, tronbosia).

- Irizpide analitikoak: leukozitosia $>20 \times 10^{9} / \mathrm{L}$, neutrofiloak $>15 \times 10^{9} / \mathrm{L}$, eosinofilia, basofilia, monozitosia $>1,0 \times 10^{9} / \mathrm{L}$, zitopeniak agertzen baldin badira arrazoi ezagunik gabe (anemia edo tronbopenia), hemoglobina edo/eta hematokritoa altuak baldin badira (emakumezkoetan $\mathrm{Hb}>16,0 \mathrm{~g} / \mathrm{dL}-\mathrm{H}$ to $>\% 48$ eta gizonezkoetan $\mathrm{Hb}>16,5 \mathrm{~g} / \mathrm{dL}-\mathrm{H}$ to $>\%$ 49), edo tronbozitosia $>450 \times 10^{9} / \mathrm{L}$. 
Jat. art. Ceberio, Furundarena, Uresandi, Arrue, Arrizabalaga, Glez, Contreras,Diez, Sukia, Orube, Araiz

\subsection{Linfozitosia (1-2,5-8)}

Kontuan hartu beharreko irizpide analitikoak

Irizpide analitikoa: linfozitoak > $5 \times 10^{9} /$ L.

Laborategiak odol periferikoaren morfologia egingo du kasu hauetan: linfozitoak $>5 \times 10^{9} / \mathrm{L}$ eta leukozitoen formulatik > \% 50 (morfologiaren txostenean zehaztuko da hematologiako kontsultara deribatzea gomendatzen den ala ez).

\section{Kontuan hartu beharreko irizpide klinikoak}

Honako egoera hauetan linfozitosi erreaktiboa agertu daitekeela kontuan hartu:

- Linfozitosi akutua / subakutua: sindrome mononukleosikoa (Epstein-Barr birusa, zitomegalobirusa, toxoplasma, barizela-zoster birusa, hepatitis birikoak, GIB), tuberkulosia, sifilia, estresagatiko linfozitosia (miokardioko infartu akutua, shock septikoa, kirurgia handia), farmakoak (hidantoinak, fenotiazinak, penizilinak...) eta hipersentsibilitate-erreakzioak.

- Linfozitosi kronikoak: gaixotasun autoimmuneak, tumore solidoak, tabakoa, inflamazio kronikoak, esplenektomia...

\section{Jarraipena lehen mailako osasun-zentroan egiteko irizpideak}

Honako kasu hauetan linfozitosiaren jarraipena osasun-zentroan bertan egingo da:

- Irizpide klinikoak: linfozitosi erreaktiboetan. Biriasiagatik dela edo iragankorra dela pentsatzen baldin badugu, hemograma errepikatu 4-6 astera.

- Irizpide analitikoak: linfozitosi poliklonaletan ez da beharrezkoa jarraipena egitea. Ondorengo kasuetan hemograma bat egingo da urtean behin: B linfozitosi poliklonal iraunkorra linfozito binukleatuekin, linfozito handi granularren linfozitosiak eta B linfozitosi monoklonalak LLK tipikoaren fenotipoarekin.

\section{Hematologiako kontsulta ez-presentziala noiz egin}

Honako irizpide hauek baloratuko dira:

- Irizpide klinikoak. Ondoren aipatzen diren edozein zeinu edo sintomagatik: linfozitosia justifikatzen duen arrazoirik aurkitzen ez baldin bada, B sintomak (pisu-galera, sukarra arrazoirik gabe edo izerditze nabarmena), adenopatiak, esplenomegalia edo infekzio errepikakorrak.

- Irizpide analitikoak: linfozitoen kopurua $>10 \times 10^{9} / \mathrm{L}$, linfozitoen kopurua urtebete baino lehen bikoiztu egiten baldin bada, zitopeniak agertzen baldin badira arrazoi ezagunik gabe (anemia, tronbopenia edo leukopenia), odoleko morfologian edo markatzaile linfozitarioen azterketan hemopatia susmatzen baldin bada.

\subsection{Neutropenia (1-2,9-10)}

Kontuan hartu beharreko irizpide analitikoak

Irizpide analitikoa: neutrofiloak $<1,5 \times 10^{9} / \mathrm{L}$.

Laborategiak odol periferikoaren morfologia egingo du kasu hauetan: neutrofiloak $<1,0 \times 10^{9} / \mathrm{L}$ eta aurretik egindako beste hemograman neutrofiloak $>1,0 \times 10^{9} / \mathrm{L}$.

Beste hemograma bat egin 2-3 astera. 
Analitika hauek eska daitezke: ANA, faktore erreumatoidea eta PCR gaixotasun autoimmuneen susmoa baldin badago, odol periferikoaren morfologia, B12 bitamina, folato serikoa, immunoglobulinak eta GIB birusa.

\section{Kontuan hartu beharreko irizpide klinikoak}

Neutropenia ager daiteke honako arrazoi hauengatik: infekzio birikoak, sepsiak, farmakoak (metamizola, antipsikotikoak, omeprazola...), gaixotasun autoimmuneak, B12 eta azido folikoaren eskasia larriak, aplasia eta hezur-muineko infiltrazio tumorala.

Farmako horiek ez hartzea baloratu.

Kontuan hartu neutropenia konstituzionala edo neutropenia onbera etnikoa. Jaiotzatik neutrofiloak < $1,5 \times 10^{9} / \mathrm{L}$ izan daitezke honako jatorri hauek dituzten pertsonen kasuan: Afrika, Karibe, Ekialde Hurbila eta Ameriketako arraza beltzekoak.

\section{Jarraipena lehen mailako osasun-zentroan egiteko irizpideak}

Honako kasu hauetan neutropeniaren jarraipena osasun-zentroan bertan egingo da, hemograma urtean behin eginda:

- Irizpide klinikoak: paziente asintomatikoa.

- Irizpide analitikoak: beste zitopeniarik ez dagoenean, neutrofiloak $>1,0 \times 10^{9} / \mathrm{L}$ direnean, kaukasikoetan edo neutrofiloak $>0,5 \times 10^{9} / \mathrm{L}$ direnean neutropenia konstituzionalean.

\section{Hematologiako kontsulta ez-presentziala noiz egin}

Irizpide hauek baloratuko dira:

- Irizpide klinikoak. Ondoren aipatzen diren edozein zeinu edo sintomagatik: infekzio errepikakorrak, B sintomak (pisu-galera, sukarra arrazoirik gabe edo izerditze nabarmena), adenopatiak, esplenomegalia edo sukar neutropenikoa (sukarra eta neutropenia $<1,0 \times 10^{9} / \mathrm{L}$ daudenean larrialdietara bideratu).

- Irizpide analitikoak: neutrofiloen kopurua $<1,0 \times 10^{9} / \mathrm{L}$ kaukasikoetan edo neutrofiloak $<0,5$ $\times 10^{9} / \mathrm{L}$ neutropenia konstituzionalean, zitopeniak agertzen baldin badira arrazoi ezagunik gabe (anemia edo tronbopenia) edo odoleko morfologian hemopatia susmatzen baldin bada.

\subsection{Monozitosia (1-2)}

\section{Kontuan hartu beharreko irizpide analitikoak}

Irizpide analitikoa: monozitoak $>1,0 \times 10^{9} / L$ eta leukozitoen formulatik $>\% 10$.

Laborategiak odol periferikoaren morfologia egingo du kasu hauetan: monozitoak $>1,5 \times 10^{9} / \mathrm{L}$ eta leukozitoen formulatik $>\% 15$ edo monozitoak $>1,0 \times 10^{9} / \mathrm{L}$ eta displasiaren susmoa (morfologiaren txostenean zehaztuko da hematologiako kontsultetara deribatzea gomendatzen den ala ez).

Baieztatu ea 3 hilabetera monozitosiak jarraitzen duen ala ez.

\section{Kontuan hartu beharreko irizpide klinikoak}

Kontuan hartu monozitosi erreaktiboa sor dezaketen arrazoiak: infekzio bakteriano kronikoak (tuberkulosia, sukar tifoideoa, endokarditis bakteriano subakutua...), infekzio birikoak (zitomegalobirusa, barizela-zoster birusa...), gaixotasun autoimmuneak (artritis erreumatoidea, lupus eritematoso sistemikoa, kolitis ultzeraduna, sarkoidosia), neoplasiak, bestelakoak (esplenektomia, glukokortikoideak, hipotiroidismoa, hesteetako gaixotasun inflamatorioa...). 
Jat. art. Ceberio, Furundarena, Uresandi, Arrue, Arrizabalaga, Glez, Contreras,Diez, Sukia, Orube, Araiz Honako kasu hauetan monozitosiaren jarraipena osasun-zentroan bertan egingo da hemograma urtean behin eginda edo/eta monozitosia sortzen duen arrazoiaren kontrola eginez:

- Irizpide klinikoak: monozitosi erreaktiboak, paziente asintomatikoa.

- Irizpide analitikoak: beste zitopeniarik ez dagoenean, morfologian displasiarik atzematen ez denean.

Hematologiako kontsulta ez-presentziala noiz egin

Honako irizpide hauek baloratuko dira:

- Irizpide klinikoak. Ondoren aipatzen diren edozein zeinu edo sintomagatik: B sintomak (pisugalera, sukarra arrazoirik gabe edo izerditze nabarmena), adenopatiak edo esplenomegalia.

- Irizpide analitikoak: zitopeniak agertzen baldin badira arrazoi ezagunik gabe (anemia, neutropenia edo tronbopenia), leukozitosia (neutrofiloak $>7,5 \times 10^{9} / \mathrm{L}$ ), eosinofilia, tronbozitosia $>450 \times 10^{9} / \mathrm{L}$ edo odoleko morfologian hemopatia susmatzen baldin bada (laborategiko txostenean horrela jakinaraziko da).

\subsection{Tronbozitosia (1-2)}

\section{Kontuan hartu beharreko irizpide analitikoak}

Irizpide analitikoa: plaketak $>450 \times 10^{9} /$ L gutxienez bi hemogramatan.

Beste hemograma bat egin 4-6 astera plaketa kopuru altuaren jarraipena baieztatzeko.

Ondorengo analitikak eska daitezke: globuluen jalkiera-abiadura, C proteina erreaktiboa eta ferritina.

Kontuan hartu beharreko irizpide klinikoak

Kontuan hartu tronbozitosi erreaktiboa sor dezaketen arrazoiak: infekzioa, prozesu inflamatorioa, neoplasia, ferropenia, esplenektomia, kirurgia.

\section{Jarraipena lehen mailako osasun-zentroan egiteko irizpideak}

Honako kasu hauetan tronbopeniaren jarraipena osasun-zentroan bertan egingo da:

- Irizpide klinikoak: tronbozitosi erreaktiboak, paziente asintomatikoa.

- Irizpide analitikoak: poliglobuliarik eta leukozitosirik ez.

Tronbozitosia sortzen duen prozesuaren jarraipena egingo da.

Hematologiako kontsulta ez-presentziala noiz egin

Honako irizpide hauek baloratuko dira:

- Irizpide klinikoak. Ondoren aipatzen diren edozein zeinu edo sintomagatik: aurrekarietan tronbosi arteriala edo tronbosi benosoa izan denean, sintoma neurologikoak, klinika hemorragikoa edo esplenomegalia.

- Irizpide analitikoak: tronbozitosia $>450 \times 10^{9} / \mathrm{L}$ mantentzen denean arrazoi ezagunik gabe, hemoglobina altua bada (emakumezkoetan $\mathrm{Hb}>16,0 \mathrm{~g} / \mathrm{dL}-$ Hto $>\% 48$ eta gizonezkoetan $\mathrm{Hb}>16,5 \mathrm{~g} / \mathrm{dL}-\mathrm{Hto}>\% 49$ ), leukozitosia $>10,5 \times 10^{9} / \mathrm{L}$ edo basofilia.

Infekzio-iturria kutsatutako elikagaien bidezkoa da. Amaren infekzioaren ondorioz, eta odolean zehar zabaltzen den infekzioa dela-eta, bakterioa, plazenta zeharkatu eta fetua infektatzeko gai da $(2,4)$. 


\section{Ondorioak}

Hematologiako kontsultetan artatutako paziente askori urtez urte hematologiako kontsultetan egin zaie jarraipena eta haietako gehienek ez dute inoiz gaixotasun hematologikorik garatu. Hematologiako gaixotasunik ezean, ez zaigu egokia iruditzen paziente bat hematologiako kontsultetara etorraraztea analitikan alterazio bat izateagatik: pertsona hori ospitalera bideratzen dugu, gaixotasun hematologikoa duela pentsarazten diogu eta espezialistaren kontsultak ez dio aparteko onurarik ekartzen. Beraz hobetzeko asko duen medikuntza bat egiten ari ginela iruditu zitzaigun.

Horregatik kontsulta-arrazoiak aztertu eta patologia hematologikoak ez diren sei alterazio analitiko usuenak aukeratu genituen. Ondoren, lantalde bat sortu zen alterazio horietan egin beharreko azterketak erabakitzeko eta pertsona horien jarraipena lehen mailan edo hematologiako kontsultetan egiteko irizpideak biltzeko. Irizpide guztiak biltzen dituen dokumentu adostua ekarri dugu artikulu honetara.

Irizpide horiek eta dokumentua dinamikoa izatea gustatuko litzaiguke. Dokumentuak lana hobeto egiten lagundu beharko luke eta erabiltzen hasi ahala sortuko diren galderekin edo moldatu beharreko puntuekin dokumentua berritu eta eguneratuko dugu. Hematologiaren eta lehen arretako osasun-zentroen artean sortu den bertaratu gabeko kontsultak dokumentuan bilduta ez dauden egoerak edo/eta sortuko diren kezkak argitzen lagunduko duela ere iruditzen zaigu. Lehen arretaren eta medikuntza espezializatuaren arteko elkarlana bultzatzeko dokumentua izatea gustatuko litzaiguke, betiere pazientearen ongizatea ardatz harturik.

\section{Bibliografia}

1. Sanz MA, Carreras E. Manual práctico de hematología clínica. 5 ed. Molins de Rei: Ediciones Escofet-Zamora; 2015.

2. Haematology Department Southend University Hospital NHS Foundation Trust. General Practice Referral Guidelines [Internet]. March 2014 [cited 2017-10-25]. 13 p. Available from: http://www.southend.nhs.uk/media/22256/referralguidelineshaematology.pdf

3. Rawstron AC, Jones RA, Ferguson C, Hughes G, Selby P, Reid C, Dalal S, Howard M, Smith G, Hillmen $P$, Owen RG, Jack AS. Outreach monitoring service for patients with indolent B-cell and plasma cell disorders: a UK experience. Br J Haematol. 2007 Dec; 139(5):845-8.

4. Uddin Z, Maennle D, Russell K, Boltri JM. Monoclonal gammapathy of undetermined significance: Using risk stratification to guide follow-up. J Fam Pract. 2015 Jul;64(7):E5-E12.

5. Moreno C. Factores de riesgo de progresión en la linfocitosis B monoclonal y la leucemia linfática crónica en fase inicial. In: LVIII Congreso Nacional de la SEHH. United Nations Office on Drugs and Crime. World Drug Report 2015. Vienna: United Nations publication, Sales No. E.15.XI.6; 2015.

6. Kalpadakis C, Pangalis GA, Sachanas S, Vassilakopoulos TP, Kyriakaki S, Korkolopoulou P, Koulieris $E$, Moschogiannis $M$, Yiakoumis $X$, Tsirkinidis $P$, Kyrtsonis MC, Levidou G, Papadaki HA, Panayiotidis P, Angelopoulou MK. New insights into monoclonal B-cell lymphocytosis. Biomed Res Int. 2014;2014:258917. doi: 10.1155/2014/258917

7. Bareau B, Rey J, Hamidou M, Donadieu J, Morcet J, Reman O, Schleinitz N, Tournilhac O, Roussel $M$, Fest T, Lamy T. Analysis of a French cohort of patients with large granular lymphocyte leukemia: a report on 229 cases. Haematologica. 2010 Sep;95(9):1534-41. doi: 10.3324/haematol.2009.018481.

8. Sokol L, Loughran TP Jr. Large granular lymphocyte leukemia. Oncologist. 2006 Mar;11(3):263-73.

9. Ortiz MV, Meier ER, Hsieh MM. Identification and Clinical Characterization of Children With Benign Ethnic Neutropenia. J Pediatr Hematol Oncol. 2016 Apr;38(3):e140-3. doi: 10.1097/MPH.0000000000000528.

10. Thobakgale CF, Ndung'u T. Neutrophil counts in persons of African origin. Curr Opin Hematol. 2014 Jan;21(1):50-7. doi: 10.1097/MOH.0000000000000007. 